\title{
Calmodulin Regulates Synaptic Plasticity in the Anterior Cingulate Cortex and Behavioral Responses: A Microelectroporation Study in Adult Rodents
}

\author{
Feng Wei, ${ }^{1,2}$ Xia-Ming Xia, ${ }^{1}$ Jianrong Tang, ${ }^{1}$ Hushan Ao, ${ }^{1}$ Shanelle Ko, ${ }^{1,3}$ Jason Liauw, ${ }^{1}$ Chang-Shen Qiu, ${ }^{1}$ and \\ Min Zhuo ${ }^{1,3}$ \\ 'Departments of Anesthesiology, Anatomy and Neurobiology, and Psychiatry, Washington University School of Medicine, St. Louis, Missouri 63110, \\ ${ }^{2}$ Department of Oral and Craniofacial Biological Sciences, University of Maryland Dental School, Baltimore, Maryland 21201, and ${ }^{3}$ Department of \\ Physiology, University of Toronto, Toronto, Canada, M5S 1A8
}

\begin{abstract}
We developed a microelectroporation method for the transfer of genes into neurons in the cerebral cortex of adult rodents, both rats and mice. We selectively expressed either green-fluorescent protein (GFP) or a $\mathrm{Ca}^{2+}$-binding deficient calmodulin (CaM) mutant in the anterior cingulate cortex (ACC). In mice that expressed GFP, positive neuronal cell bodies were found specifically at the injection site in the ACC. Mice that expressed $\mathrm{CaM}_{12}$, a mutant $\mathrm{CaM}$ with two impaired $\mathrm{Ca}^{2+}$ binding sites in the $\mathrm{N}$-terminal lobe, exhibited significant changes in vocalization, locomotion, and sensory functions. Long-term potentiation and long-term depression, two major forms of central plasticity, were completely abolished by expression of $\mathrm{CaM}_{12}$. Mice that expressed $\mathrm{CaM}_{34}$, a mutant $\mathrm{CaM}$ with two impaired $\mathrm{Ca}^{2+}$ binding sites in the C-terminal lobe, did not show any significant behavioral or electrophysiological alterations. These findings provide strong evidence that $\mathrm{CaM}$ is critical for bidirectional synaptic plasticity. This new method will be useful for investigating gene function in specific brain regions of freely moving animals. Furthermore, this approach also may facilitate gene therapy in adult human brains.
\end{abstract}

Key words: calmodulin; electroporation; gene transfer; anterior cingulate cortex; synaptic plasticity; mice

\section{Introduction}

Genomic investigations, in both humans and other organisms, have identified numerous genes possibly involved in various brain functions, including development, memory, and drug addiction, as well as various brain disorders. The ability to transfer any gene of interest to a specific brain region in a timely manner would greatly facilitate characterizing the functions of these genes in adult animals and identifying potential therapeutic targets for human diseases. In animals, several approaches have been used to target gene transfer to neurons in vivo, including the use of adenoviral-based vectors (for review, see During and Ashenden, 1998; Costantini et al., 2000; Luo and Saltzman, 2000) and liposomal-plasmid complexes (Schwarze et al., 1999; Shi and Pardridge, 2000). More recently, electroporation, an application of brief electrical pulses to tissue, has been used to temporarily increase cellular permeability to DNA. Electroporation has been successfully used to enhance gene delivery into cells of adult or-

\section{Received Feb. 4, 2003; revised July 16, 2003; accepted July 16, 2003.}

This work was supported by National Institute of Neurological Disorders and Stroke Grant 38680, National Institute on Drug Abuse Grant 10833, the McDonnell Center for Higher Brain Function at Washington University, and the EJLB-Canadian Institutes of Health Research Michael Smith Chair in Neurosciences and Mental Health. We thank Drs. Louis J. Muglia, Yi Rao, and Zhou-Feng Chen for helpful suggestions. Proofreading and editing were provided by Dr. Dana Beitner-Johnson at BiomedEditors (Cincinnati, $\mathrm{OH}$ ).

Correspondence should be addressed to either of the following: Dr. Min Zhuo, Department of Physiology, 1 King's College Circle, University of Toronto, Toronto, Canada, M5S 1A8, E-mail: min.zhuo@utoronto.ca; or Dr. Feng Wei, Department of Oral and Craniofacial Biological Sciences, University of Maryland Dental School, 666 West Baltimore Street, Baltimore, MD 21201, E-mail: fwei001@umaryland.edu.

Copyright $\odot 2003$ Society for Neuroscience $\quad 0270-6474 / 03 / 238402-08 \$ 15.00 / 0$ gans, such as skeletal muscle (Aihara and Miyazaki, 1998; Vicat et al., 2000), as well as neurons in the brains of embryonic chicks (Itasaki et al., 1999; Nakamura et al., 2000; Yasuda et al., 2000) and embryonic mice (Fukuchi-Shimogori and Grove, 2001; Saito and Nakatsuji, 2001; Tabata and Nakajima, 2001). Electroporation has also been used to effectively transfer genes into single targeted neurons in brain slices (Haas et al., 2001). However, the use of electroporation to deliver genes into adult mammalian brains has not been reported.

Electroporation in the adult mammalian CNS would provide a valuable method to study various physiological and pathological processes in the mammalian brain. First, it would enable selective delivery of a gene to specific regions of the CNS. Unlike a transgenic approach, it also provides a method for unilateral gene transfer. Second, electroporation in adult brain would provide a way to express a gene at any time during the development of normal or pathophysiological processes. The role of signaling proteins in numerous brain functions, such as the induction and consolidation of memory, the maintenance of persistent pain, cortical reorganization after amputation, or nerve regeneration after injury, could be investigated. This approach also provides a method to rescue behavioral defects in genetically altered mice. Third, electroporation has fewer toxic effects compared with other methods of gene transfer, such as viral gene transfer or the "gene gun" technique. Fourth, transferring the Cre-recombinase gene in mice with a floxed allele may provide a novel tool for generating region-specific gene knock-out mice. Finally, elec- 
trozporation may be useful for delivering gene therapy to patients with brain tumors.

In this study, we adapted the electroporation method and showed the expression of both green fluorescent protein (GFP) and mutant calmodulin (CaM) in the anterior cingulate cortex (ACC). This microelectroporation technique will allow selective regional expression of specific genes and proteins in adult mammalian brains.

\section{Materials and Methods}

In vivo microelectroporation. cDNA constructs encoding wild-type CaM and mutant $\mathrm{CaM}_{12}, \mathrm{CaM}_{34}$, and $\mathrm{CaM}_{1234}$ were transferred from pBF to the mammalian expression vector pJPA7 (Xia et al., 1998). To prepare the DNA for electroporation, the standard molecular procedures were followed. Briefly, after isopranol precipitation, the DNA was fished out with a yellow tip and rinsed in 70\% ethanol. Then the DNA was dissolved in Tris-EDTA and precipitated again; these steps were repeated more than three times to obtain highly purified DNA. At the end, the DNA was rinsed in $70 \%$ ethanol several times for desalting, dried, and dissolved in double-distilled water to reach the final concentration of $1 \mu \mathrm{g} / \mu \mathrm{l}$.

Adult male mice (C57BL/6J; 20-25 gm; The Jackson Laboratory, Bar Harbor, ME) or rats (Sprague Dawley; 280-380 gm; Harlan Sprague Dawley, Indianapolis, IN) were maintained in a temperature- and lightcontrolled room in an animal facility, with food and water available ad libitum. The animals were anesthetized with $2 \%$ halothane and placed in a David Kopf Instruments (Tujunga, CA) stereotaxic apparatus fitted with a mouse adaptor that positioned the skull horizontally between bregma and lambda. DNA was injected into the ACC of mice at the following coordinates: $0.7 \mathrm{~mm}$ anterior to bregma, $0.4 \mathrm{~mm}$ lateral from the midline, and at a depth of $1.8 \mathrm{~mm}$ from the skull surface. A volume of $0.5 \mu \mathrm{l}$ of concentrated vector $\left(1 \times 10^{6}\right.$ particles/ $\left.\mu \mathrm{l}\right)$ was injected into each site at a rate of $0.05 \mu \mathrm{l} / \mathrm{min}$ using a 30 gauge beveled needle with cannula tubing connected to a Hamilton syringe mounted on a microinjection pump. In most experiments, the ACC was bilaterally injected with GFP $(0.5 \mu \mathrm{l} /$ each side), a mixture of GFP and mutant CaM (1:1 in a volume of $0.5 \mu \mathrm{l}$ ), or enhanced GFP (eGFP) fused in-frame at the $\mathrm{N}$ or $\mathrm{C}$ terminal of CaM $(0.5 \mu 1 ; n=8)$. The needle was left in place for $15 \mathrm{~min}$ before being slowly withdrawn. All surgical procedures were performed under sterile conditions and in accordance with Guidelines for the Animal Care and Use approved by the Washington University School of Medicine.

For microelectroporation, square-wave electric pulses were delivered by a Grass Instruments (Quincy, MA) SD9 Stimulator with an isolation unit. A pair of silver electrodes (60 gauge) was placed $3 \mathrm{~mm}$ anterior and $2 \mathrm{~mm}$ posterior to the injection site, respectively ( $2.5 \mathrm{~mm}$ depth). The silver electrodes were not insulated or chloridized. In preliminary experiments, we tested different electrical parameters for optimal transfection of GFP gene in the ACC. We found the following optimal stimulation paradigms: five pulses delivered at $1 \mathrm{~Hz}(50 \mathrm{msec}$ duration at $50 \mathrm{~V})$ or a $100 \mathrm{msec}$ train stimulation at $200 \mathrm{~Hz}$ ( $1 \mathrm{msec}$ duration at $20 \mathrm{~V})$. During the electroporation, no motor response was observed. After the gene electroporation, we did not observe any seizure-like activity in animals.

Immunohistochemistry. For immunohistochemical staining, brain sections were prepared on a cryostat and incubated with the following antibodies: polyclonal anti-GFP (1:500; Clontech, Palo Alto, CA) and anti-CaM (1:1000; Chemicon, Temecula, CA), monoclonal antimitogen-activated protein (MAP2) (1:500; Chemicon), and anti-glial fibrillary acidic protein (GFAP) (1:500; Chemicon). Goat anti-species antibodies conjugated to Alexa 488 and 568 (1:200-500; both from Molecular Probes, Eugene, OR) were used for immunofluorescent labeling. Terminal deoxynucleotidyl transferase-mediated biotinylated UTP nick end labeling (TUNEL) staining was measured with an in situ cell death detection kit (Roche Molecular Biochemicals, Mannheim, Germany). Brain sections were mounted with Vectashield media (Vector Laboratories, Burlingame, CA) and analyzed by fluorescence microscopy and laser scanning confocal microscopy (Fluowview 2.19; Olympus Optical, Tokyo, Japan). For the DAB reaction, some sections were processed with the Vector $\mathrm{ABC}$ kit (Vector Laboratories). CaM expression was quan- tified on every sixth section by the optical fractionator procedure (Wei et al., 2002). The images were processed using Adobe PhotoShop 5.5 (Adobe Systems, Mountain View, CA). In some experiments, we also used the integrated density to quantify staining results; with the aid of Scion (Frederick, MD) Image program, the intensity of density or the sum of the gray values in the selection, with background subtracted, was computed using the following formula: integrated density $=N$ (number of pixels in the section $) \times$ (mean density - background $)$.

Behavioral measurements. Locomotor activity was measured using an open-field activity monitor $(43.2 \times 43.2 \times 30.5 \mathrm{~cm}$; Med Associates, Albans, VT). Each subject was placed in the center of the open field, and activity was measured for $30 \mathrm{~min}$. Ultrasonic vocalizations were detected using four mini-3 ultrasonic detectors (Ultrasound Advice, London, UK), each tuned to a different frequency level ranging from 30 to 120 $\mathrm{kHz}$. The detectors were suspended $19 \mathrm{~cm}$ from the floor of the openfield activity monitor. Ultrasonic vocalizations were measured using UltraVox data acquisition software (Noldus, Sterling, VA). The animals' behaviors in the elevated plus maze were measured using an elevated plus maze (Med Associates). The duration of time animals spent in the open arm versus closed arms was recorded. To test acute sensory responses, the latency of response to heating of the tail (tail-flick reflex) or to placement on a hot plate $\left(55^{\circ} \mathrm{C}\right)$ was measured as described previously (Wei et al., 2002).

Slice electrophysiology. Transverse slices of the ACC were rapidly prepared and maintained in an interface chamber at $28^{\circ} \mathrm{C}$, in which they were subfused with artificial CSF (ACSF) consisting of the following: (in mм) $124 \mathrm{NaCl}, 4.4 \mathrm{KCl}, 2.0 \mathrm{CaCl}_{2}, 1.0 \mathrm{MgSO}_{4}, 25 \mathrm{NaHCO}_{3}, 1.0$ $\mathrm{Na}_{2} \mathrm{HPO}_{4}$, and 10 glucose (bubbled with $95 \% \mathrm{O}_{2}$ and $5 \% \mathrm{CO}_{2}$ ). Slices were kept in the recording chamber for at least $2 \mathrm{hr}$ before the start of experiments. A bipolar tungsten stimulating electrode was placed in layer $\mathrm{V}$ of the ACC, and extracellular field potentials were recorded using a glass microelectrode (3-12 M $\Omega$, filled with ACSF) placed in layer II-III. Five trains of theta burst stimulation (TBS), which consisted of five bursts (four pulses at $100 \mathrm{~Hz}$ ) of stimuli delivered every $200 \mathrm{msec}$ at the same intensity, were applied to induce long-term potentiation (LTP). A low-frequency, prolonged stimulation $(1 \mathrm{~Hz}, 15 \mathrm{~min})$ was used to induce long-term depression (LTD). Synaptic responses were elicited at $0.02 \mathrm{~Hz}$. In some experiments, intracellular recordings were also performed with glass microelectrodes filled with $2 \%$ neurobiotin- $2 \mathrm{M}$ potassium chloride (80-200 M $\Omega$ ). After electrophysiological characterization, cells were injected with neurobiotin ( $+3.0 \mathrm{nA}, 150 \mathrm{msec}, 3.3 \mathrm{~Hz}$ for $5 \mathrm{~min})$. The slices then fixed in $4 \%$ paraformaldehyde $30 \mathrm{~min}$ after the injection. Morphological procedures were used to stain and identify the recorded cells.

Data analysis. Results were expressed as mean \pm SEM. Statistical comparisons included one- or two-way ANOVA with the post hoc Scheffe $F$ test in immunocytochemical experiments or the Student-NewmanKeuls test in behavioral experiments. In all cases, $p<0.05$ was considered to be statistically significant.

\section{Results}

We focused on the ACC in this study because of its important role in many higher brain functions (Devinsky et al., 1995; Price, 2000; Allman et al., 2001; Paus, 2001; Peoples, 2002) and because relatively little is known about the essential molecular and cellular signaling mechanisms in this area. To evaluate the possibility of using microelectroporation for neuronal gene transfer in adult animals, we combined a microinjection of naked DNA encoding GFP with local electrical stimulation in the ACC of adult mice under anesthesia (Fig. $1 A, B$ ). In preliminary experiments, we tested different electrical parameters (i.e., the frequency and duration of stimulating pulses) to optimize transfection of the GFP gene in the ACC. The optimal stimulation paradigms were found to be either five pulses delivered at $1 \mathrm{~Hz}(50 \mathrm{msec}$ duration at $50 \mathrm{~V})$ or a $100 \mathrm{msec}$ train stimulation at $200 \mathrm{~Hz}(1 \mathrm{msec}$ duration at $20 \mathrm{~V})$.

We collected brain samples between 1 and $14 \mathrm{~d}$ after the microelectroporation of GFP and performed immunohistochemistry. Three days after the treatment, high levels of GFP expression 

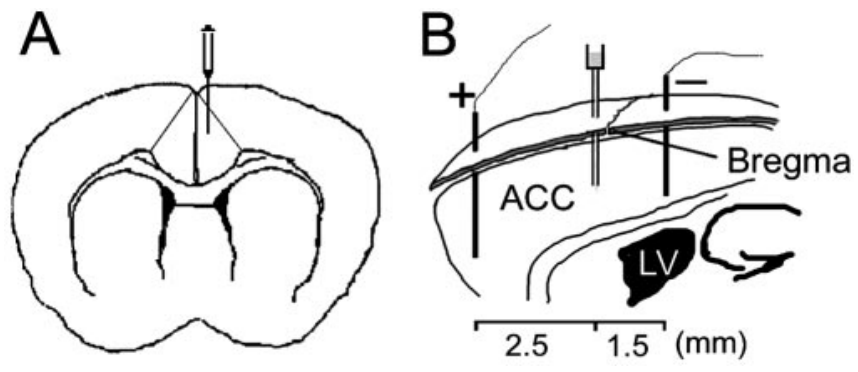

Figure 1. The overall design of microinjection and electroporation in the ACC. A, Coronal section of the mouse forebrain through the $A C C$ showing the placement of the microinjection in vivo. $B$, Location of the stimulating electrodes rostral and caudal to the injection site. LV, Lateral ventricle.

A

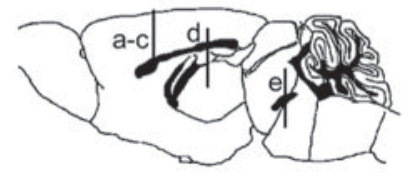

ACC
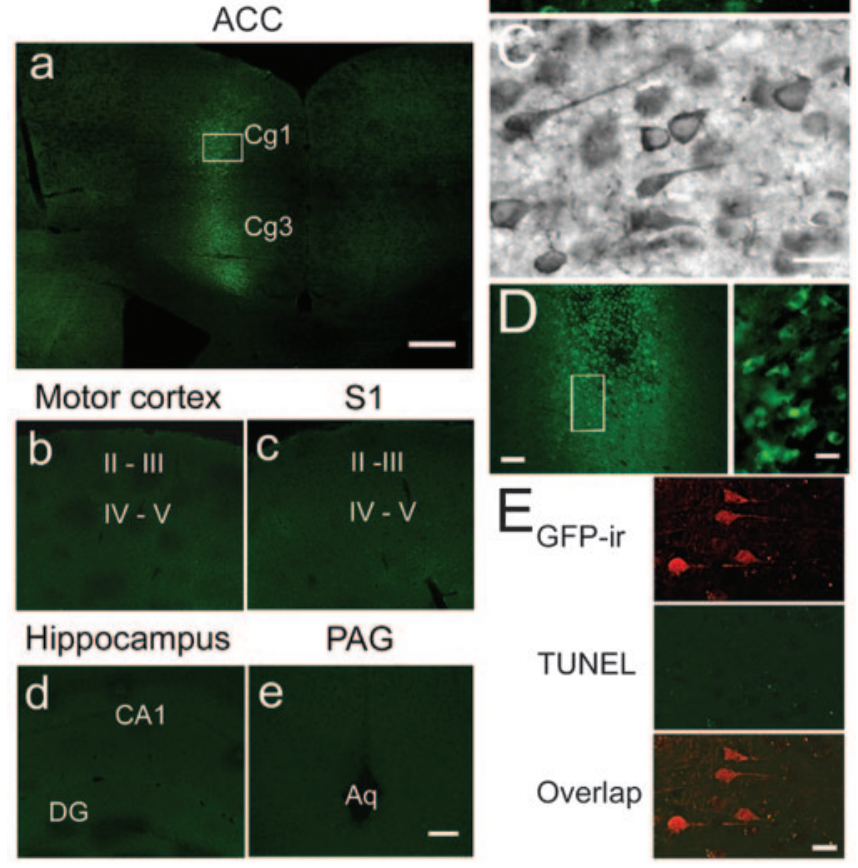

Figure 2. GFP expression in the ACC of adult mice and rats by electroporation. $A$, Representative brain sections positioned in several regions showing GFP-labeled neurons only in the ipsilateral ACC ( $a)$ but not motor cortex $(b)$, somatosensory cortex $(S 1 ; C)$, hippocampus $(d)$, and periaqueductal gray (PAG; $e$ ). $B$, High magnification illustrates GFP expression of the inset marked in a. C, Immunostaining with GFP antibody shows GFP expression in dendrites in pyramidal neurons in layer II-III of the ACC. D, Expression of GFP in the ACC of adult rats. E, With TUNEL costaining, few cells underwent apoptosis in the targeted ACC. Scale bars: $A a, 200 \mu \mathrm{m}$; $A b-A e, D$ (left panel), $100 \mu \mathrm{m} ; B, 25 \mu \mathrm{m} ; C, D$ (right panel), $E, 20 \mu \mathrm{m}$.

were found in the ACC ( $n=7$ mice) (Fig. $2 A-C$ ). Because of the expression of GFP in both soma and nerve terminals, we calculated the GFP-positive area as a percentage of the total area of the ACC to estimate the levels of GFP expression. The highest level of GFP expression was usually found within five sections $(20 \mu \mathrm{m}$ thickness) of the injection site (from 58.0 to $99.0 \%$ ). GFP expression was significantly lower at greater distances ( $>5$ sections) from the injection site (13-29\%). We also counted the numbers of GFP-positive cells within each section. We found that that the majority of GFP-positive cells were localized within the ACC (bregma -0.5 to $-0.6 \mathrm{~mm}$, mean $21 \pm 9$ cells per section; bregma +0.5 to $+0.6 \mathrm{~mm}, 376 \pm 92$ cells per section; and bregma +2.1 to $+2.2 \mathrm{~mm}, 87 \pm 30$ cells per section; $n=4-5$ mice). No GFP-positive staining was detected in the adjacent motor cortex, striatum, lateral septal areas, piriform, prelimbic, or restrosplenial cortices. Furthermore, no GFP expression was detected in related areas, including the somatosensory cortex, hippocampus, thalamus, or periaqueductal gray of the midbrain (Fig. 2A). Thus, the expression of GFP was highly restricted to the injected area. We also performed double staining with the neuronal marker MAP2 or the mircoglia marker GFAP to determine whether GFP expression was localized in neurons or glia within the ACC. We found that GFP was predominantly expressed in neurons. Expression of GFP in microglia was observed at later times (e.g., $14 \mathrm{~d}$ ) after gene delivery. No GFP expression was detected in mice microinjected with GFP DNA in the absence of electrical stimulation ( $n=3$ mice).

To determine whether this microelectroporation procedure could also be applied to rats, we performed the same experiments in the ACC of adult rats. Microelectroporation induced high levels of GFP expression in the ACC $(n=5$ rats) (Fig. $2 D)$. Similar to the findings in adult mice, GFP expression was highly specific to the ACC, and no immunostaining was detected in other brain areas examined.

One critical issue related to microelectroporation is whether the electrical stimulation itself can induce significant changes in neuronal function or even neuronal death. In our experiments, we used the same electrodes that have been used previously to deliver identical stimulation intensity to brain slices for in vitro experiments. This type of stimulation is not known to cause any type of neuronal injury when delivered at either low or high frequency $(1-100 \mathrm{~Hz}$, for durations from a few seconds to 15 min). We used two different methods to further evaluate possible pathological injury attributable to electrical stimulation. First, we used TUNEL staining to label cells undergoing apoptosis (Gavrieli et al., 1992; White et al., 1998). Double staining for GFP and TUNEL revealed no evidence of extensive cell death within the ACC between stimulation electrodes (Fig. 2E). However, TUNEL-positive staining was detected in areas around the tracks of the stimulators, which served as a positive control for TUNEL under these experimental conditions.

We next used sensory and motor behavioral tests to determine whether mice expressing GFP exhibited behavioral alterations compared with sham-treated animals. Mice expressing GFP did not exhibit any sign of behavioral convulsions after the surgery. Similar postoperative changes in body weight were found in sham and GFP-injected mice (sham group, $n=8$ mice; GFP expression group, $n=12$ mice). In the hot plate test, both groups of animals showed similar escape latencies at two different temperatures $\left(50^{\circ} \mathrm{C}\right.$, sham, $30.0 \pm 0.5 \mathrm{sec}$; GFP, $28.8 \pm 1.0 \mathrm{sec} ; 55^{\circ} \mathrm{C}$, sham, $13.2 \pm 0.4 \mathrm{sec}$; GFP, $13.7 \pm 0.7 \mathrm{sec})$. We also measured the locomotor activity of mice in an open-field chamber. No significant differences were found between the two groups during a 30 min observation time (data not shown). Thus, microelectroporation can be used to selectively express a gene in a selected brain area without inducing major behavioral side effects.

To determine whether microelectroporation of a mammalian signaling gene can induce physiological and behavioral changes in rodents, we expressed a mutant CaM protein in the ACC. CaM is a ubiquitous and highly conserved $\mathrm{Ca}^{2+}$-binding protein. As a major $\mathrm{Ca}^{2+}$-signaling mediator, CaM plays a critical role in nu- 
merous vital physiological functions, including fertilization, cell proliferation, development, and learning and memory (Cyert, 2001; Hoeflich and Ikura, 2002; Saimi and Kung, 2002). CaM regulates various intracellular protein kinases and phosphatases in response to increases in intracellular $\mathrm{Ca}^{2+}$ levels attributable to activation of membrane receptors (e.g., NMDA receptors) or opening of ion channels (e.g., L-type voltage-gated calcium channels). CaM target proteins, such as $\mathrm{Ca}^{2+} / \mathrm{CaM}$-dependent protein kinase II (CaMKII), CaM-activated adenylyl cyclases, and the CaM-activated phosphatase calcineurin, are known to be important for synaptic plasticity and behavioral learning and memory (Malenka and Nicoll, 1999; Kandel, 2001; Lisman et al., 2002). Recent genetic studies have consistently demonstrated that CaM-dependent protein kinases and phosphatases play important roles in synaptic plasticity, such as long-term potentiation and depression, as well as cognitive functions (Silva et al., 1998; Malenka and Nicoll, 1999; Kandel, 2001; Lisman et al., 2002). Genetic studies of CaM have proven to be more difficult than studies of its target proteins. No natural CaM mutant has ever been found. CaM point mutations have been generated, but these have only been studied in yeast, Paramecium, and Drosophila (Hinrichsen et al., 1986; Ohya and Bostein, 1994; Nelson et al., 1997). CaM null mutants in these species are lethal (Davis et al., 1986; Heiman et al., 1996), and survival of CaM knock-out mice has not been reported.

Four calcium-binding sites have been identified on the two lobes of CaM. Electrophysiological studies using Xenopus oocytes or HEK293 cells showed that impairment of the $\mathrm{Ca}^{2+}$ binding sites on each of the two lobes of CaM specifically disrupted the function or unique features of potassium and calcium channels (Xia et al., 1998; DeMaria et al., 2001). Fewer studies have attempted to identify physiological roles of the $\mathrm{Ca}^{2+}$-binding $\mathrm{EF}$ hands of CaM in the CNS. Next, we microinjected DNA encoding either wild-type $\mathrm{CaM}$ or $\mathrm{CaM}$ with mutations in two or four of the $\mathrm{Ca}^{2+}$-binding $\mathrm{EF}$ hands $\left(\mathrm{CaM}_{12}, \mathrm{CaM}_{34}\right.$, or $\left.\mathrm{CaM}_{1234}\right)(\mathrm{Fig}$. $3 A$ ) into the ACC of adult mice. In preliminary experiments, we found that Western blots did not show any obvious changes in CaM protein levels in ACC slices (data not shown). It is possible that Western blotting may not be sufficiently sensitive to detect changes in CaM levels in selected ACC cells. Thus, we next used immunohistochemistry to determine whether changes in CaMlike activity could be detected within certain areas of the ACC. Using this approach, we found that unilateral injection of mutant CaM caused an obvious increase in CaM immunoreactivity specifically in the targeted ACC (integrated density, $10.7 \pm 1.7 ; n=$ 5 ) relative to that of the contralateral side $(1.4 \pm 0.3)$ (Fig. $3 B, C$ ). To further verify the expression of recombinant $\mathrm{CaM}$ in the ACC, we used eGFP fused in-frame at the $\mathrm{N}$ or $\mathrm{C}$ terminal of CaM. With in-frame fusion at the $\mathrm{N}$ terminal of CaM, we found that GFPpositive ACC cells expressed stronger immunostaining for $\mathrm{CaM}$ $(n=8)$ (Fig. 3D). Fusions at the C-terminal of CaM with eGFP did not result in significant expression of either GFP or CaM (data not shown).

Costaining with selective neuronal and glial markers showed that the majority of CaM staining was localized within ACC neurons $3 \mathrm{~d}$ after microelectroporation (Fig. 3E). The expressed mutant CaM was found primarily within the cytoplasm and not in nuclei, which is consistent with the fact that CaM is mainly expressed in the cytoplasm under resting conditions (Deisserorth et al., 1998; Wei et al., 2002).

To further determine whether the mutant CaM was effectively expressed in the ACC, we performed various behavioral experiments to see whether mice overexpressing mutant CaM exhibited

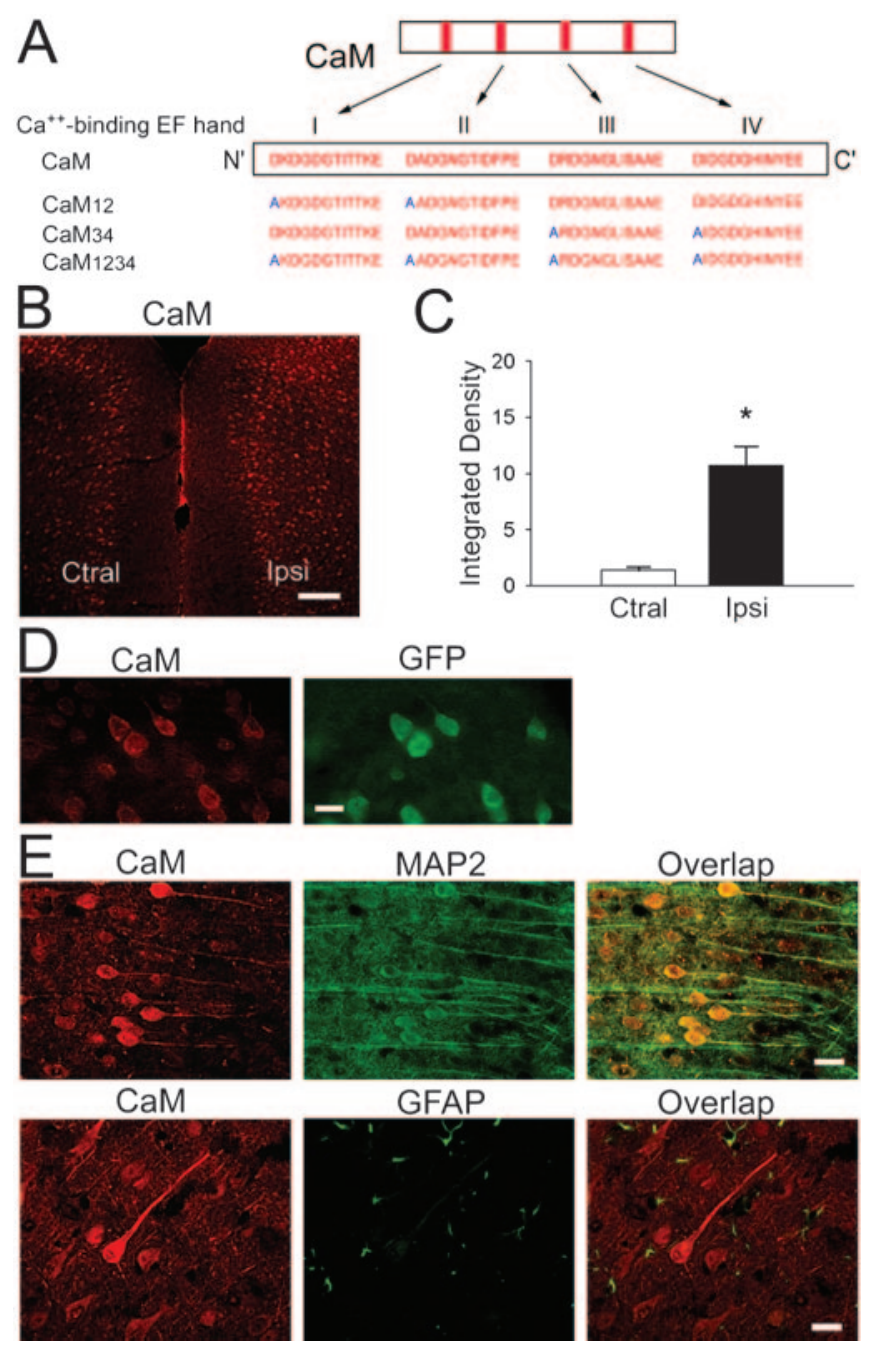

Figure 3. $\mathrm{CaM}_{12}$ expression in the $\mathrm{ACC}$. $A$, Vector constructs of $\mathrm{DNA}$ encoding $\mathrm{Ca}^{2+}$-binding deficient CaM isoforms. $B$, Enhanced CaM immunostaining attributable to $\mathrm{CaM}_{12}$ expression in the ipsilateral ACC.C, The densiometric analysis of CaM immunostaining shown in B.D, Colocalization of CaM immunostaining of CaM and GFP expression in the same section at $3 \mathrm{~d}$ after

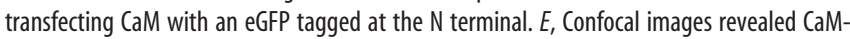
labeled cells coexpressing MAP2 but not GFAP. Scale bars: B, $200 \mu \mathrm{m} ; D, E, 20 \mu \mathrm{m}$. Ctral, Contralateral; Ipsi, ipsilateral.

any abnormal behavior patterns. The ACC and related prefrontal cortex are known to play roles in at least three major physiological functions: emotion-related activity, such as vocalization, locomotor functions, and sensory perception, including pain (Devinsky et al., 1995; Rainville et al., 1997; Hutchison et al., 1999; Price, 2000; Allman et al., 2001; Paus, 2001; Wei and Zhuo, 2001; Peoples, 2002; Zhuo, 2002). To determine whether expression of the various mutant forms of CaM altered the animals' behavior and to identify possible functional roles of the four $\mathrm{Ca}^{2+}$ binding sites in CaM, we first evaluated ultrasonic vocalization of mice in an open-field chamber. Vocalization is widely used for communication between animals and serves as an index for various emotional states, including injury, defense, escape, and pleasure. Previous studies suggested that the ACC plays an important role in vocalization related to emotion and anxiety in humans and animals (Smith, 1945; Allman et al., 2001). We hypothesized that disruption of the $\mathrm{Ca}^{2+} / \mathrm{CaM}$-dependent signaling pathway may affect ACC function by altering vocalization behavior in mice expressing the CaM mutants. 


\section{A Vocalization}
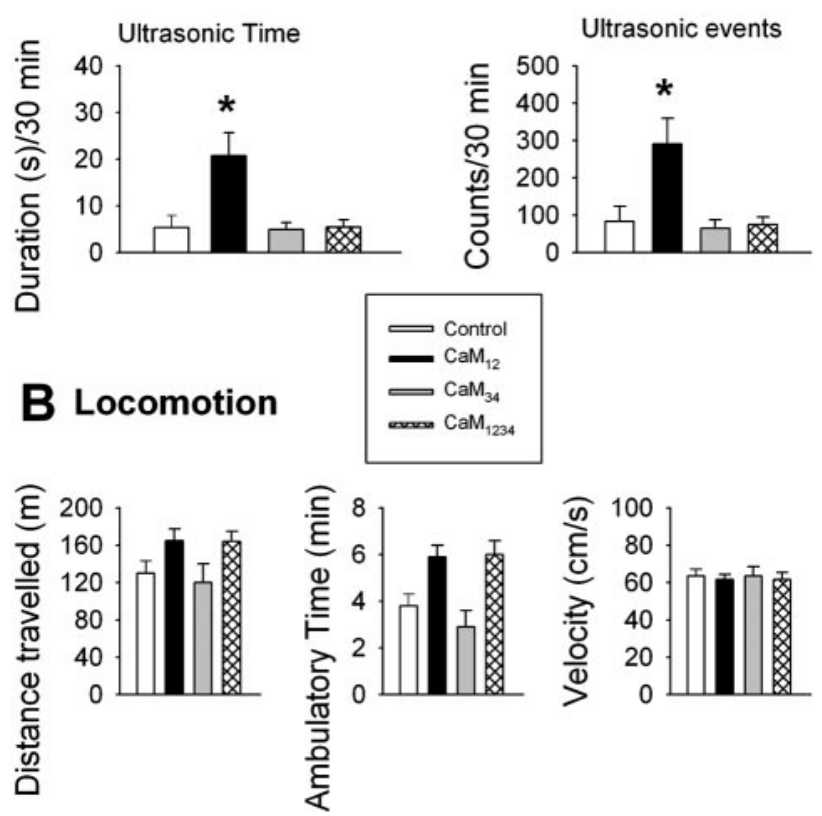

\section{Sensory Response}
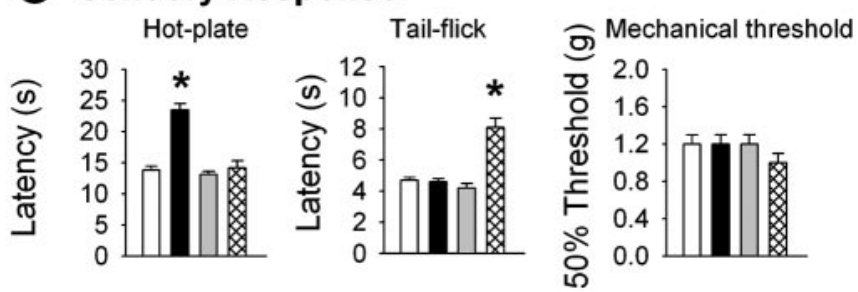

Figure 4. Behavioral effects of mutant CaM expression in the ACC of adult mice. $A$, Elevated ultrasonic vocalization activity in mice with $\mathrm{CaM}_{12}$ overexpression (left, the total vocalization duration; right, the total vocalization events). $B, \mathrm{CaM}_{12}$ or $\mathrm{CaM}_{1234}$ overexpression significantly increased the total traveled distance and ambulatory time without effect on velocity. C, Behavioral response latencies in a hot plate test, spinally mediated tail-flick reflex, and hindpaw withdrawal to mechanical stimulation.

Among the various mutants, we found that expression of $\mathrm{CaM}_{12}$ in the ACC significantly enhanced spontaneous ultrasonic vocalization activity $(n=12$ mice) (Fig. $4 A)$. The total duration of vocalization during a $30 \mathrm{~min}$ period was significantly higher in $\mathrm{CaM}_{12}$ mice $(20.7 \pm 4.9 \mathrm{sec})$ compared with control GFP mice $(5.3 \pm 2.6 \mathrm{sec} ; p<0.001)$ (Fig. $4 A$ ). The effect of $\mathrm{CaM}_{12}$ on vocalization was frequency dependent, with the greatest increase displayed at 30 and $50 \mathrm{kHz}$. The total number of ultrasonic events was also significantly increased in $\mathrm{CaM}_{12}$ mice (Fig. $4 A$ ). No significant differences were found between the $\mathrm{CaM}_{34}$ or $\mathrm{CaM}_{1234}$ mice and control groups, suggesting that these effects on vocalization are relatively selective for the $\mathrm{CaM}_{12}$ mutant. As an additional test for emotion, we also measured animals' behaviors in the elevated plus maze and found no significant difference between control GFP $(n=7)$ and $\mathrm{CaM}_{12}(n=5)$ mice.

Second, we measured locomotor activity in control and mutant CaM mice. Whereas the average moving velocity of mice was not significantly different in any of the mutant CaM mice compared with controls ( $n=4-12$ mice) (Fig. $4 B)$, the total distance traveled was higher in mice expressing $\mathrm{CaM}_{12}$ or $\mathrm{CaM}_{1234}(n=$ 4-12 mice) (Fig. $4 B$ ). Mice expressing the $\mathrm{CaM}_{12}$ or $\mathrm{CaM}_{1234}$ mutants spent less time at rest and more time being ambulatory compared with GFP-expressing control mice (Fig. 4B). No such differences were observed in mice expressing $\mathrm{CaM}_{34}$.

Finally, we performed three different sensory tests and found that $\mathrm{CaM}_{12}$, but not $\mathrm{CaM}_{34}$ or $\mathrm{CaM}_{1234}$, caused significant changes in the hot plate response to noxious heat. Mice expressing $\mathrm{CaM}_{12}$ in the ACC were less sensitive to noxious stimulation in the hot plate test (Fig. 4C). No changes in the tail-flick reflex or the hindpaw mechanical withdrawal thresholds were found, except that $\mathrm{CaM}_{1234}$ expression also caused changes in tail-flick response latencies (Fig. 4C).

The behavioral findings described above clearly indicate that expression of mutant CaM can cause significant changes in ACCrelated physiological functions. To determine whether mutant $\mathrm{CaM}$ also induces changes at the synaptic level, we performed electrophysiological experiments to evaluate neuronal membrane excitability and synaptic plasticity in the ACC. First, considering the important role of CaM-dependent protein kinases and phosphatases in synaptic plasticity, we studied potential changes in synaptic responses to repetitive TBS. Electrophysiological recordings from animals and humans have revealed that ACC neurons are likely to fire action potentials at $4-7 \mathrm{~Hz}$ (theta) during various behavioral tests (Smith, 1945; Gevins et al., 1997; Hutchison et al., 1999; Suetsugi et al., 2000). We therefore performed electrophysiological experiments in ACC slices from control and CaM mutant mice. Similar to previous studies in normal brain slices (Wei et al., 2002), TBS caused significant synaptic potentiation in ACC slices from mice subjected to microelectroporation, and the enhanced responses lasted for at least $45 \mathrm{~min}$ in GFP-expressing slices ( $n=6$ slices from 4 mice) (Fig. $5 A$ ). This finding is consistent with the behavioral observations that expression of GFP alone did not cause any significant changes in ultrasonic vocalization or locomotor activity of mice. In contrast to the findings in GFP-expressing mice, the TBS-induced potentiation was completely absent in slices from GFP-CaM $\mathrm{C}_{12}$ mice ( $n=9$ slices from 6 mice; mean of $100.1 \pm 14.4 \%$ relative to baseline) (Fig. 5A). No obvious differences in baseline field synaptic responses were detected ( $n=18$ slices from 10 mice for GFP mice; $n=16$ slices from 9 mice for GFP-CaM ${ }_{12}$ mice). We also measured LTP in GFP-CaM ${ }_{34}$ and GFP-CaM ${ }_{1234}$ mice. In brain slices from GFP-CaM ${ }_{34}$ mice, a long-lasting enhancement of synaptic responses was observed ( $n=5$ slices from 3 mice; mean of $143.2 \pm 6.8 \%$ ) (Fig. 5B). However, in slices from GFP-CaM 1234 mice, TBS induced no significant potentiation $(n=6$ slices from 4 mice; mean of $105.7 \pm 24.1 \%$ ).

LTD, which can be induced by repetitive low-frequency stimulation, has been reported to occur in many brains regions, including the ACC (Wei et al., 1999). We also examined whether the expression of mutant CaMs had any effect on LTD. Whereas $1 \mathrm{~Hz}$ stimulation (for $15 \mathrm{~min}$ ) significantly reduced synaptic responses in ACC slices from mice that received GFP injections ( $n=6$ slices from 4 mice; mean of $69.1 \pm 12.6 \%$ ) (Fig. $5 C$ ), no such depression was detected in ACC slices from GFP-CaM 12 mice ( $n=5$ slices from 3 mice; mean of $105.1 \pm 7.8 \%$ ) (Fig. $5 C$ ). In contrast, $1 \mathrm{~Hz}$ stimulation $(15 \mathrm{~min})$ readily induced LTD in slices obtained from GFP-CaM ${ }_{34}$ mice $(n=5$ slices from 3 mice; mean of $66.3 \pm 19.1 \%)$ or GFP-CaM ${ }_{1234}$ mice $(n=6$ slices from 5 mice; mean of $81.1 \pm 6.1 \%$ ) (Fig. $5 D$ ). To measure possible changes at other stimulation frequencies, we applied the same number of pulses at two other frequencies ( 5 and $10 \mathrm{~Hz}$ ). Again, no significant differences were found among control and mutant groups at both testing frequencies $(n=4-7$ slices from at least 3 mice per group) (Fig. 6).

These studies demonstrate that $\mathrm{CaM}_{12}$ caused changes in sev- 

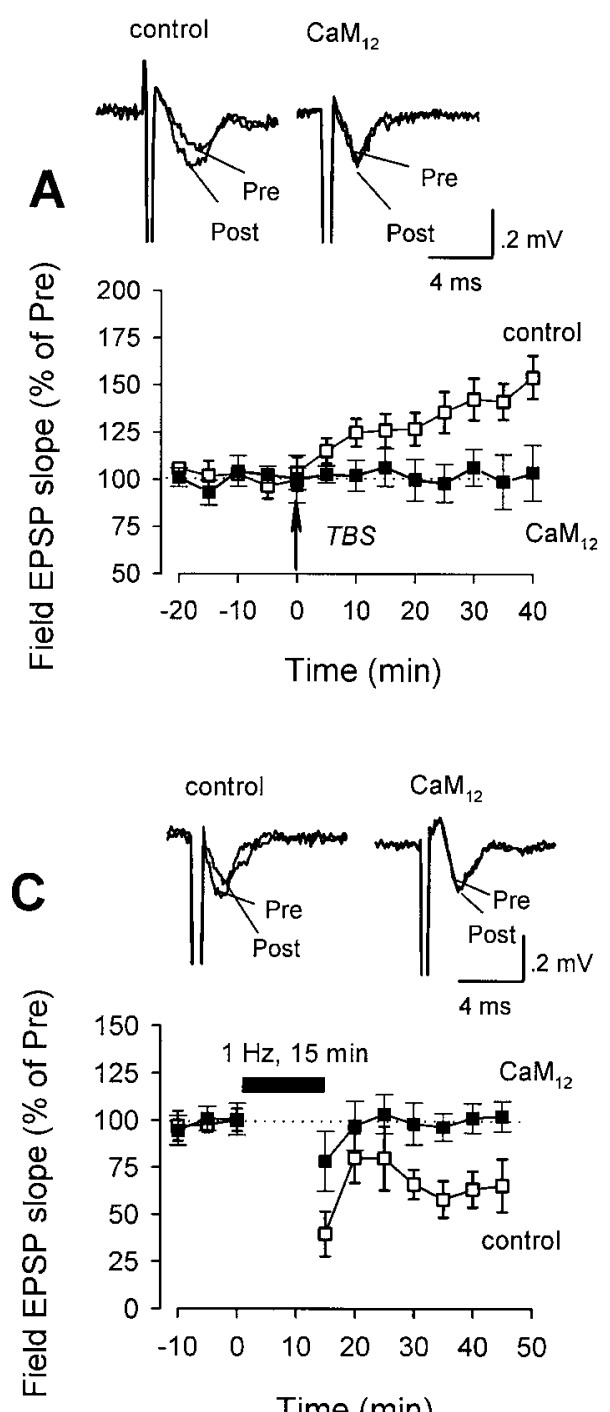

Time $(\min )$
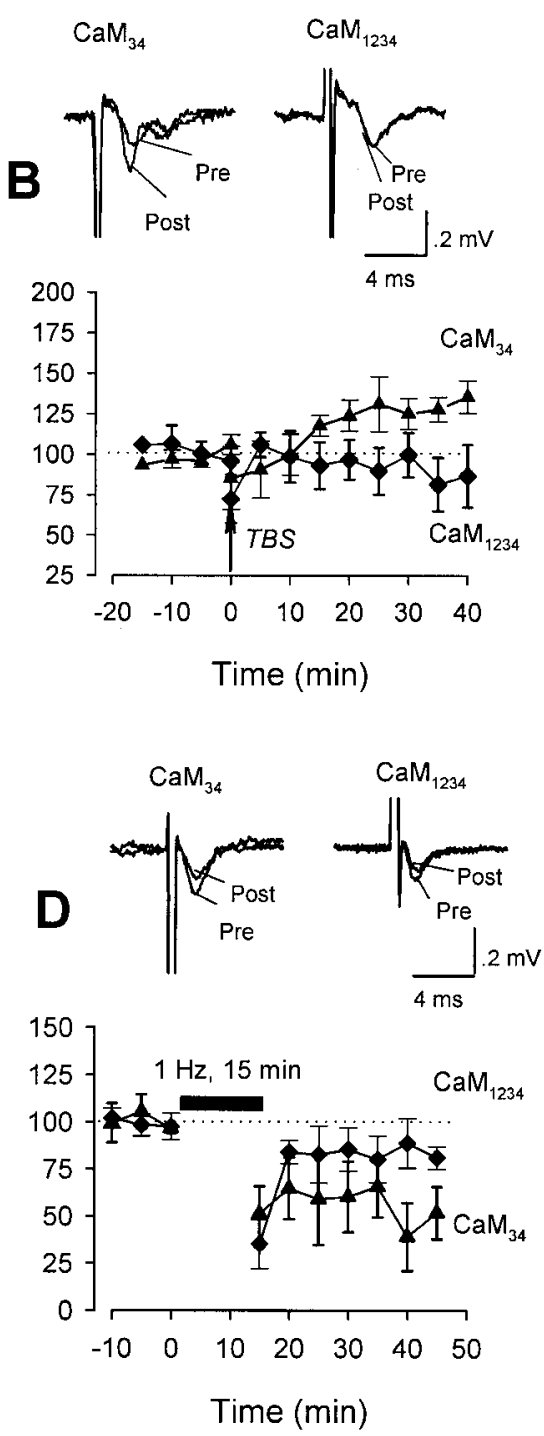

Figure 5. Effects of mutant CaM on ACC synaptic plasticity. $A, B$, Elimination of synaptic potentiation in slices from CaM 12 (filled squares) or $\mathrm{CaM}_{1234}$ expression (filled diamonds) compared with control (open squares) or $\mathrm{CaM}_{34}$ expression (filled triangles) mice. Inset, Representative records of the field EPSP before (Pre) and 40 min after (Post) TBS. C, D, Long-term depression, induced by low-frequency stimulation ( $1 \mathrm{~Hz}, 15 \mathrm{~min}$ ), was also blocked in slices from CaM $\mathrm{C}_{12}$ expression mice. Inset, Representative records of the field EPSP before (Pre) and $30 \mathrm{~min}$ after (Post) $1 \mathrm{~Hz}$ (15 min) stimulation.

eral parameters of behavior and synaptic plasticity. Thus, we next asked whether $\mathrm{CaM}_{12}$ expression alters the neuronal spiking properties of ACC neurons. To do this, we made intracellular recordings from GFP-expressing cells under a fluorescence microscope (Fig. 7A-C). No significant changes were observed in neuronal spiking in response to direct current injection. Similarly, resting membrane potentials were identical between cells

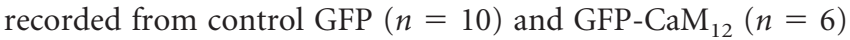
brain slices. Furthermore, the current threshold for eliciting the first spike was similar in control and mutant slices $(n=3$ cells for each group), and the number of spiking induced by injection of $0.3 \mathrm{nA}$ was also identical ( $n=6-10$ cells). These results indicate that $\mathrm{CaM}_{12}$ expression did not cause any major changes in the intrinsic neuronal electrophysiological properties of ACC neurons.

\section{Discussion}

Through the use of microelectroporation, we showed that it is possible to overexpress a gene in a specific brain region of adult rats and mice. Our findings provide strong physiological evidence that ACC neurons contribute to specific motor and sensory functions, which is consistent with previous studies in humans. The overexpression of a CaM mutant with impaired $\mathrm{Ca}^{2+}$ binding to the $\mathrm{N}$-terminal lobe in the ACC of mice significantly altered ultrasonic vocalization, locomotor activity in an open field, and sensory responses to noxious heat applied to the hindpaw. Because the mutant $\mathrm{CaM}$ includes changes in only two of the $\mathrm{Ca}^{2+}$ binding sites within CaM, these results suggest that the fine regulation of $\mathrm{Ca}^{2+} / \mathrm{CaM}$ signaling pathways play important roles in ACC-related physiological functions. Although our results consistently indicate that the $\mathrm{Ca}^{2+}$-binding sites of the CaM N-terminal $\left(\mathrm{CaM}_{12}\right)$ lobe are functionally important, the contribution of $\mathrm{Ca}^{2+}$ binding sites of the CaM C-terminal $\left(\mathrm{CaM}_{34}\right)$ lobe for ACC-related behavioral responses remain uncertain. Clearly, the $\mathrm{Ca}^{2+}$ binding sites of the CaM C-terminal $\left(\mathrm{CaM}_{34}\right)$ lobe play different roles in ACC-related functions and in the functions of potassium channels and P/Qtype $\mathrm{Ca}^{2+}$ channels (Xia et al., 1998; DeMaria et al., 2001). Because of limitation in the sensitivity of our biochemical assays, we do not know the exact amount of the expression of $\mathrm{CaM}_{12}, \mathrm{CaM}_{34}$, and $\mathrm{CaM}_{1234}$ in the ACC. Future studies are needed to address the exact mechanism contributing to their physiological effects.

$\mathrm{CaM}$ is thought to be the key molecule for controlling synaptic changes, in terms of both potentiation and depression (Malenka and Nicoll, 1999; Kandel, 2001; Lisman et al., 2002). It is hypothesized that, although high $\mathrm{Ca}^{2+}$ levels lead to synaptic potentiation, moderate increases in $\mathrm{Ca}^{2+}$ levels lead to short-term potentiation or long-term depression of synaptic transmission. Inhibition of NMDA receptors or L-type voltage-gated calcium channels, which are key membrane receptors and channels for $\mathrm{Ca}^{2+}$ influx during periods of high synaptic activity, blocked both synaptic potentiation and depression in many brain regions (Bear, 1996; Malenka and Nicoll, 1999; Wei et al., 1999). In the present studies, we found that expression of $\mathrm{CaM}_{12}$ in the ACC blocked TBS-induced LTP. Previous studies using mice that lack CaMKIV, a key protein kinase downstream of CaM, showed that CaMKIV is critical for synaptic potentiation in the ACC (Wei et al., 2002). Together, these results strongly suggest that calcium/CaM-dependent signaling pathways play an important role in LTP in the ACC. In addition to synaptic potentiation, it has been hypothesized that CaM also serves as a key sensor for synaptic depression triggered by changes in the magnitude or dynamics of increases in postsynaptic $\mathrm{Ca}^{2+}$ (Lisman, 1989; Bear, 1996), although there is no direct evidence that CaM is involved. In the ACC, low-frequency stimulation produced LTD of synaptic responses, and activation of both L-type voltage-gated calcium channels and metabotropic 
A

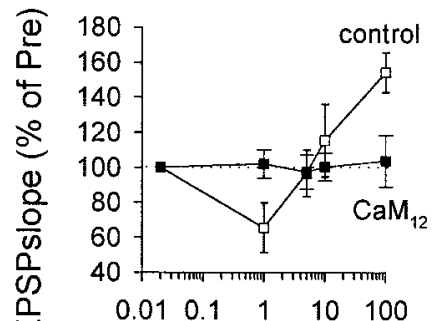

Frequency $(\mathrm{Hz})$

\section{B}

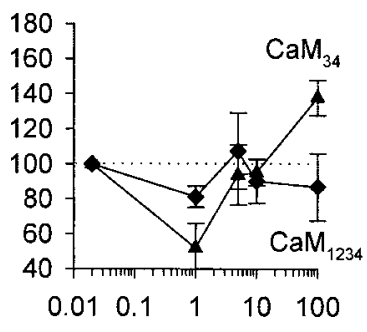

Frequency $(\mathrm{Hz})$

Figure 6. Synaptic plasticity induced by stimulation at different frequencies. $A$, Summary data for synaptic potentiation, synaptic depression, and synaptic responses at other frequencies ( 5 and $10 \mathrm{~Hz}$ with the same total 900 pulses). CaM $_{12}$ expression blocked both LTP (filled squares) induced by theta burst stimulation and LTD by $1 \mathrm{~Hz}$ stimulation. $B$, Summary data of $\mathrm{CaM}_{34}$ (filled triangles) and $\mathrm{CaM}_{1234}$ (filled diamonds) expression experiments. Open squares, Control mice.

A
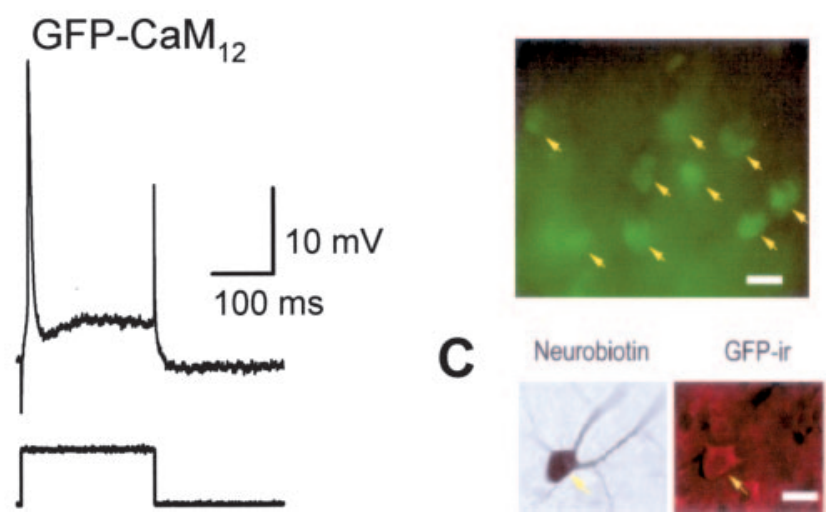

Figure 7. Effects of $\mathrm{CaM}_{12}$ on postsynaptic neuronal excitability. A, An example of spike responses of a GFP-CaM $\mathrm{C}_{12}$-expressing cell recorded with a sharp electrode. $B, \mathrm{GFP}^{-} \mathrm{CaM}_{12}{ }^{-}$ expressing cells (indicated by arrows) in an ACC slice from an adult mouse. C, A cell filled with intracellular neurobiotin (left) and costaining for GFP (right). Scale bars, $20 \mu \mathrm{m}$.

glutamate receptors are required for the induction of LTD in the ACC (Wei et al., 1999). Here, we found that ACC LTD was blocked in $\mathrm{CaM}_{12}$-expressing mice. Our present results provide strong evidence that CaM serves as a key signaling protein in bidirectional synaptic plasticity in the ACC. Furthermore, we also show, for the first time, that the first two $\mathrm{Ca}^{2+}$ binding sites on the CaM N-terminal lobe are essential for both LTP and LTD. Although synaptic plasticity was significantly altered, we did not observe any significant changes in soma excitability, such as the generation of action potentials in response to injected currents. It is quite possible that a more complete elimination of CaM would cause more pronounced changes in neuronal properties such as spiking.

It is important to point out that there are certain limitations related to the mechanisms by which mutant CaM induces these alterations. First, it is not known how mutant CaM affects downstream signaling pathways. Many protein kinases and phosphatases are regulated by $\mathrm{CaM}$, and additional experiments are clearly needed to determine how expression of mutant CaM may affect their activities. Second, we used the synaptic model of plas- ticity to study changes in CaM-dependent synaptic plasticity. We believe that changes in LTP-LTD cannot completely explain the changes observed in various behaviors. At the moment, it is also unclear how and if LTP and/or LTD contribute to behavioral changes such as sensory responses and ultrasonic vocalization. Because of the incomplete understanding of the cellular and molecular mechanisms involved in ACC function, more work will be needed to clarify these issues. Third, we would like to point out that overexpression of $\mathrm{CaM}_{12}$ and $\mathrm{CaM}_{1234}$ shared some features, but there were also distinct effects of the two mutants. In all three measurements of locomotor activity, $\mathrm{CaM}_{12}$ overexpression had effects similar to $\mathrm{CaM}_{1234}$ overexpression. However, in the hot plate test, overexpression of $\mathrm{CaM}_{12}$, but not $\mathrm{CaM}_{1234}$, significantly increased behavioral response latencies. At the synaptic level, overexpression of $\mathrm{CaM}_{12}$ or $\mathrm{CaM}_{1234}$ blocked LTP in the ACC. However, LTD was only blocked by expression of $\mathrm{CaM}_{12}$ and not $\mathrm{CaM}_{1234}$. These results suggest that the various $\mathrm{Ca}^{2+}$ binding sites on CaM may have specific roles in neurons.

This study is the first to show that microelectroporation can be used to express a gene in the adult mammalian brain. Unlike current transgenic approaches, microelectroporation permits overexpression of a gene within a highly specific brain region, either unilaterally or bilaterally. In combination with gene knock-out techniques, this approach can serve as a useful tool to study the molecular mechanisms underlying higher brain functions in adult animals. This may provide a new method for gene therapy in adult human brains.

\section{References}

Aihara H, Miyazaki J (1998) Gene transfer into muscle by electroporation in vivo. Nat Biotechnol 16:867-870.

Allman JM, Hakeem A, Erwin JM, Nimchinsky E, Hop P (2001) The anterior cingulate cortex. The evolution of an interface between emotion and cognition. Ann NY Acad Sci 935:107-117.

Bear MF (1996) A synaptic basis for memory storage in the cerebral cortex. Proc Natl Acad Sci USA 93:13453-13459.

Costantini LC, Bakowska JC, Breakefield XO, Isacson O (2000) Gene therapy in the CNS. Gene Ther 7:93-109.

Cyert MS (2001) Genetic analysis of calmodulin and its targets in Saccharomyces cerevisiae. Annu Rev Genet 35:647-672.

Davis TN, Urdea MS, Masiarz FR, Thorner J (1986) Isolation of the yeast calmodulin gene: calmodulin is an essential protein. Cell 47:423-431.

Deisserorth K, Heist EK, Tsien RW (1998) Translocation of calmodulin to the nucleus supports CREB phosphorylation in hippocampal neurons. Nature 392:198-202.

DeMaria CD, Soong TW, Alseilkhan BA, Alvania RS, Yue D (2001) Calmodulin bifurcates the local $\mathrm{Ca}^{2+}$ signal that modulates $\mathrm{P} / \mathrm{Q}-$ type $\mathrm{Ca}^{2+}$ channels. Nature 411:484-489.

Devinsky O, Morrell MJ, Vogt BA (1995) Contributions of anterior cingulate cortex to behaviour. Brain 118:279-306.

During MJ, Ashenden LA (1998) Towards gene therapy for the central nervous system. Mol Med Today 4:485-493.

Fukuchi-Shimogori T, Grove EA (2001) Neocortex patterning by the secreted signaling molecule FGF8. Science 294:1071-1074.

Gavrieli Y, Sherman Y, Ben-Sasson SA (1992) Identification of programmed cell death in situ via specific labeling of nuclear DNA fragmentation. J Cell Biol 119:493-501.

Gevins A, Smith ME, Mcenvoy L, Yu D (1997) High-resolution EEG mapping of cortical activation related to working memory: effects of task difficulty, type of processing, and practice. Cereb Cortex 7:374-385.

Haas K, Sin WC, Javaherian A, Li Z, Cline H (2001) Single-cell electroporation for gene transfer in vivo. Neuron 29:583-591.

Heiman RG, Atkinson RC, Andruss BF, Bolduc C, Kovalick GE, Beckingham K (1996) Spontaneous avoidance behavior in Drosophila null for calmodulin expression. Proc Natl Acad Sci USA 93:2420-2425.

Hinrichsen RD, Burgess-Cassler A, Soltvedt BC, Hennessey T, Kung C (1986) Restoration by calmodulin of a $\mathrm{Ca}^{2+}$-dependent $\mathrm{K}^{+}$current missing in a mutant of Paramecium. Science 232:503-506. 
Hoeflich KP, Ikura M (2002) Calmodulin in action: diversity in target recognition and activation mechanisms. Cell 108:739-742.

Hutchison WD, Davis KD, Lozano AM, Tasker RR, Dostrovsky JO (1999) Pain-related neurons in the human cingulate cortex. Nat Neurosci 2:403-405.

Itasaki N, Bel-Vialar S, Krumlauf R (1999) "Shocking” developments in chick embryology: electroporation and in ovo gene expression. Nat Cell Biol 1:E203-E207.

Kandel ER (2001) The molecular biology of memory storage: a dialogue between genes and synapses. Science 294:1030-1038.

Lisman J (1989) A mechanism for the Hebb and the anti-Hebb processes underlying learning and memory. Proc Natl Acad Sci USA 86:9574-9578.

Lisman J, Schulman H, Cline H (2002) The molecular basis of CaMKII function in synaptic and behavioural memory. Nat Neurosci Rev 3:175-190.

Luo D, Saltzman WM (2000) Synthetic DNA delivery systems. Nat Biotechnol 18:33-37.

Malenka RC, Nicoll RA (1999) Long-term potentiation-a decade of progress? Science 285:1870-1874.

Nakamura H, Watanabe Y, Funahashi J (2000) Misexpression of genes in brain vescles by in ovo electroporation. Dev Growth Differ 42:188-201.

Nelson HB, Heiman RG, Bolduc C, Kovalick GE, Whitley P, Stern M, Beckingham K (1997) Calmodulin point mutations affect Drosophila development and behavior. Genetics 147:1783-1798.

Ohya Y, Bostein D (1994) Diverse essential functions revealed by complementing yeast calmodulin mutants. Science 263:963-966.

Paus T (2001) Primate anterior cingulate cortex: where motor control, drive and cognition interface. Nat Neurosci Rev 2:417-424.

Peoples LL (2002) Will, anterior cingulate cortex, and addiction. Science 296:1623-1624.

Price DD (2000) Psychological and neural mechanisms of the affective dimension of pain. Science 288:1769-1772.

Rainville P, Duncan GH, Price DD, Carrier B, Bushnell MC (1997) Pain affect encoded in human anterior cingulate but not somatosensory cortex. Science 377:968-971.

Saimi Y, Kung C (2002) Calmodulin as an ion channel subunit. Annu Rev Physiol 64:289-311.

Saito T, Nakatsuji N (2001) Efficient gene transfer into the embryonic mouse brain. Dev Biol 240:237-246.
Schwarze SR, Ho A, Vocero-Akbani A, Dowdy SF (1999) In vivo protein transduction: delivery of a biologically active protein into the mouse. Science 285:1569-1572.

Shi N, Pardridge WM (2000) Non-invasive gene targeting to the brain. Proc Natl Acad Sci USA 97:7567-7572.

Silva AJ, Kogan JH, Frankland PW, Kida S (1998) CREB and Memory. Annu Rev Neurosci 21:127-148.

Smith WK (1945) The functional significance of the rostral cingular cortex as revealed by its responses to electrical excitation. J Neurophysiol 8:241-255.

Suetsugi M, Mizuki Y, Ushijima I, Kobayashi T, Tsuchiya K, Aoki T, Watanabe Y (2000) Appearance of frontal midline theta activity in patients with generalized anxiety disorder. Neuropsychobiology 41:108-112.

Tabata H, Nakajima K (2001) Efficient in utero gene transfer system to the developing mouse brain using electroporation: visualization of neuronal migration in the developing cortex. Neuroscience 103:865-872.

Vicat JM, Boisseau S, Jourdes P, Laine M, Wion D, Bouali-Benazzouz R, Benabid AL, Berger F (2000) Muscle transfection by electroporation with high-voltage and short-pulse currents provides high-level and longlasting gene expression. Hum Gene Ther 11:909-916.

Wei F, Zhuo M (2001) Potentiation of synaptic responses in the anterior cingulate cortex following digital amputation in rat. J Physiology (Lond) 532:823-833.

Wei F, Li P, Zhuo M (1999) Loss of synaptic depression in mammalian anterior cingulate cortex after amputation. J Neurosci 19:9346-9354.

Wei F, Qiu CS, Liauw J, Robinson DA, Ho N, Chatila T, Zhuo M (2002) Calcium calmodulin-dependent protein kinase IV is required for fear memory. Nat Neurosci 5:573-579.

White FA, Keller-Peck CR, Knudson CM, Korsmeyer SJ, Snider WD (1998) Widespread elimination of naturally occurring neuronal death in Baxdeficient mice. J Neurosci 18:1428-1438.

Xia X-M, Fakler B, Rivard A, Wayman G, Johnson-Pais T, Keen JE, Ishii T, Hirschberg B, Bond CT, Lutsenko S, Maylie J, Adelman JP (1998) Mechanism of calcium gating in small-conductance calcium-activated potassium channels. Nature 395:503-507.

Yasuda K, Momose T, Takahashi Y (2000) Application of microelectroporation for studies of chick embryogenesis. Dev Growth Differ 42:203-206.

Zhuo M (2002) Glutamate receptors and persistent pain: targeting forebrain NR2B subunits. Drug Discov Today 7:259-267. 